\title{
Enhancing written language skills during the year abroad through online independent learning
}

\author{
Maria Chiara La Sala ${ }^{1}$
}

Abstract

$\mathrm{T}$ his article focusses on the online independent language learning resource for the Year Abroad (YA) in Italy at the University of Leeds. The YA is an important component of most undergraduate degree programmes in Modern Languages. It increases linguistic proficiency and cultural awareness. During the last twenty years, there has been a growing body of research on L2 development of language learners Studying Abroad (SA), which focusses on the acquisition of speaking and listening skills and on intercultural competence, while the development of morpho-syntactic skills remain under researched. This article seeks to explore how Virtual Learning Environments (VLEs) can allow tutors to support the development of written language skills in the SA context. This article evaluates an online resource designed to enhance written language skills during the YA. The outcomes of the initiative will be presented and possible future developments of the online resource will be discussed.

Keywords: independent learning, online resource, written language work, year abroad, study abroad.

1. University of Leeds, Leeds, United Kingdom; illmcls@leeds.ac.uk

How to cite this chapter: La Sala, M. C. (2018). Enhancing written language skills during the year abroad through online independent learning. In R. Biasini \& A. Proudfoot (Eds), Using digital resources to enhance language learning - case studies in Italian (pp. 17-27). Research-publishing.net. https://doi.org/10.14705/rpnet.2018.24.795 


\section{Introduction}

\subsection{The context: the YA}

The common assumption about SA is that it automatically leads to greater language proficiency. However, current literature does not provide a consistent picture of how the SA experience improves linguistic competence. In particular, there is little evidence that the YA improves morpho-syntactic skills. This could be in part due to the lack of systematic study as students focus on their communicative proficiency whilst abroad.

Technology can provide language tutors with an opportunity to support and guide students' independent learning during their residence abroad. To date, little has been written in this area.

\subsection{Background information}

As in most British universities where Italian is taught, the undergraduate programme at the University of Leeds has two distinct pathways: Beginners' Programme (BA Italian B) and Advanced Programme (BA Italian A). The cohort of beginners spends one year in Italy as a compulsory part of the degree, whereas the advanced cohort may spend only a term in Italy. The final-year written language exam consists of a translation paper of two literary or journalistic texts: one from English into Italian and one from Italian into English. The second component of the final-year written language exam consists of an essay paper.

For the YA in Italy, students have the following options:

- working as a language assistant with the British Council;

- following an Erasmus study programme at a partner university;

- taking Corsi Singoli at a university not included in the Erasmus programme; and 
- doing a paid or voluntary work placement.

\subsection{The challenge}

The need to create a virtual learning environment for YA students derived from two main goals: to facilitate the transition from Level 2 to Level 3 and to give students the opportunity to enhance written language skills during their YA. Despite the common assumption that the period of residence abroad is the best environment to learn a second language (Stern, 1964), students' standards after their period of residence abroad do not always suggest that it has enhanced their written language skills. In Italy, students appear to perfect their speaking, listening, and reading skills, but not their writing. This is due in part to the context of the Italian university where most of the exams are oral and where opportunities for academic writing are rare. Collentine (2009), however, observes that this is a general issue rather than related to specific contexts or institutions:

"whereas SA (study abroad) affects gains in certain languagespecific domains, it does not affect development in all aspects of a learner's competence. Interestingly, linguistic aspects that do indeed seem to benefit from Study Abroad, such as fluency and discursive abilities, are often not those in which AH (at home) FL (foreign language) program directors hope to see improvements, such as those grammatical aspects around which the $\mathrm{AH}$, focus-on-forms syllabus is designed" (p. 224).

\section{Methodology}

\subsection{The YA online resource: Written Language Work (WLW)}

The proposed solution to the challenge outlined above was to offer structured guidance for independent learning during the YA through an online resource, the WLW resource. 
The first step in the development of the resource was to consider both the objectives and assessment methods of Level 2 and Level 3 language modules as well as the type of environment students were likely to encounter during their YA. The resource was an attempt to link more closely the two contexts for second language acquisition identified by Batstone (2002), the communicative and learning contexts:

"A communicative context is sociolinguistic in orientation. A learner focuses on the use of language to convey meaning in an appropriate fashion according to contextual cues. The target language is used as a tool to exchange information and participate in important social and interpersonal functions. In contrast, a learning context has a psycholinguistic orientation in which learners focus on form with tutor assistance with the goal of improving their linguistic expertise" (p. 4).

The resource was developed in the academic year 2013-2014 and made available in 2014-2015. Students returning from their YA in September 2015 were the first cohort to use it. It was developed with the assistance of an Erasmus intern, providing a student perspective and a guarantee that the WLW would appeal to a younger generation with digital skills.

The tasks included in the WLW are the following:

- a set of self-correcting grammar exercises;

- a set of self-correcting translation exercises (six of these to be submitted for feedback); and

- a set of writing tasks on an aspect of Italian culture and society with the title 'Compositions' (three of these to be submitted for feedback).

A screenshot of the initial page can be seen below in Figure 1. 
Figure 1. Initial page of the WLW

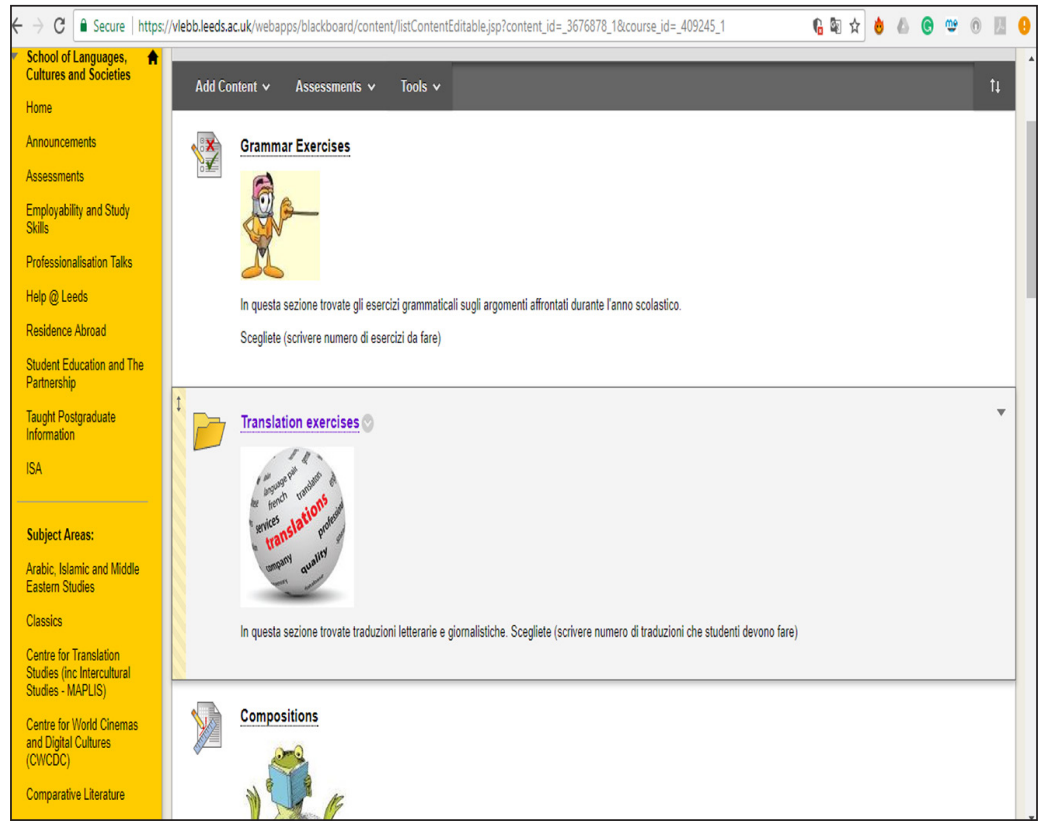

All activities were created within Blackboard Learn, which supports the University of Leeds' VLE, a learning management system familiar to students and therefore involving no additional learning workload. For the self-correcting grammar exercises and translation exercises, the Italian teaching team opted for the Blackboard Test tool, whereas for the compositions, the Blackboard Assignments tool was used. As the latter does not provide appropriate feedback, a more traditional 'one-to-one' feedback is sent to students via individual emails.

In addition to the activities in the WLW, students submit a self-reflective questionnaire and a resoconto (a written account) entitled 'La mia permanenza in Italia' (My stay in Italy), which focusses on the key aspects of the YA experience. These three elements are part of the evaluation for the YA and students, either in a study or work placement, which they must all pass to proceed to their final year. 


\subsection{Evaluation of the resource}

The WLW was evaluated through student feedback. An online questionnaire ${ }^{2}$ with a mix of closed and open questions asked students to what extent the WLW helped them make progress in written language skills and become independent learners. The questionnaire was sent to 39 students and received an $85 \%$ response rate (33 students).

The pie chart below (Figure 2) shows that $50 \%$ of the respondents thought that using the WLW had enhanced the knowledge and understanding gained from Level 2 written language seminars attended in Year 2.

A possible reason for this relatively low percentage is that the link between the content and assessment methods of the second year language course and those of the final-year language course is not explained clearly enough.

Sixty-two percent of the respondents agreed that assignments and tests available on the WLW are a useful way of making progress in written language skills during the YA (see Figure 3).

Figure 2. Question 2b

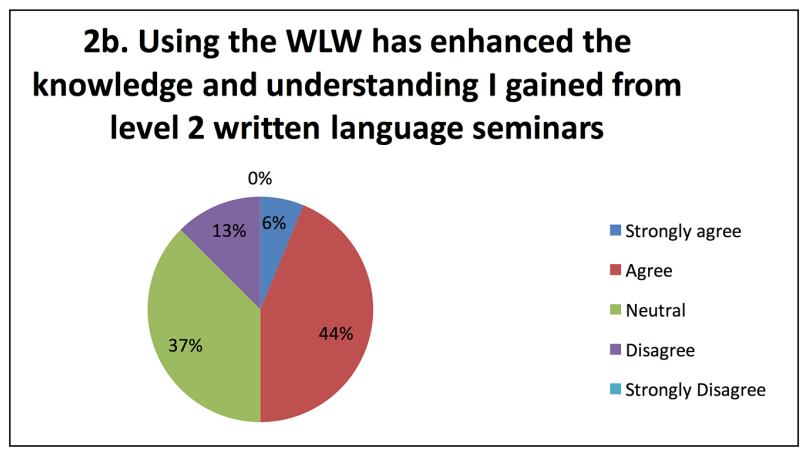

2. https://research-publishing.box.com/s/cihuzkz5v5k71k0511ghrqj1v8snr76e 
Figure 3. Question 2c

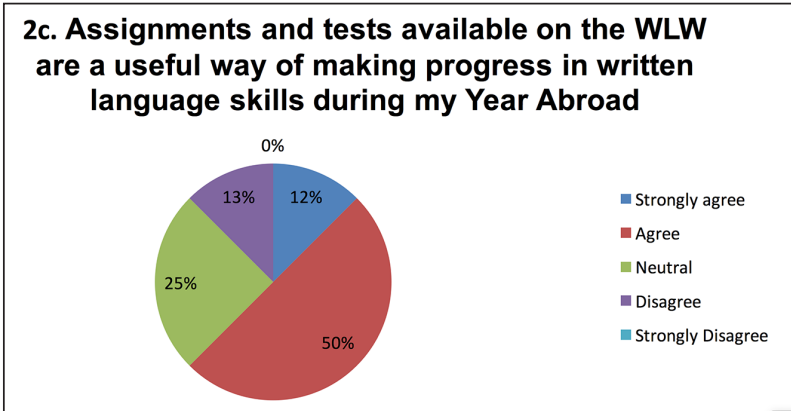

Students' responses to Question 4 are quite varied, see Figure 4.

Figure 4. Question 4

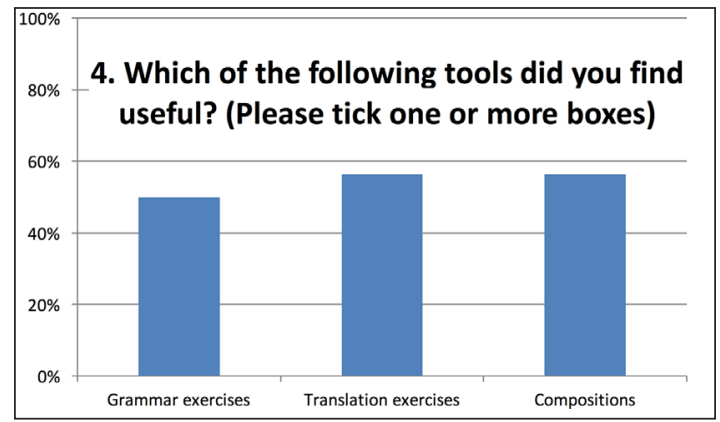

The analysis of these findings shows that while grammar exercises are appreciated by students who prefer a formal and structured approach to language learning, the writing tasks ('compositions') are preferred by those who see culture as a way of learning a second language.

Students' comments on the grammar exercises ${ }^{3}$ show students' awareness that certain grammatical constructions may not receive sufficient practice during the

3. Question 4B; https://research-publishing.box.com/s/cihuzkz5v5k71k0511ghrqj1v8snr76e 
YA and that consolidating knowledge of morphology and syntax in a short time span is a challenge inherent to the Italian beginners programme ${ }^{4}$.

\section{Discussion}

\subsection{Analysis}

The views expressed by students are in line with larger studies showing that explicitly learned rules of morpho-syntax require longer time than lexical forms to be automatised (VanPatten, 1996, p. 30).

Writing compositions on cultural topics is a way of transferring knowledge of Italian culture into the study of language and of seeing cultural and linguistic competences as part of the same coherent project. The QAA Benchmark Statements of 2015, which define what can be expected of a language graduate at the end of their studies, strongly promotes this view:

"The study of languages enables students to understand the similarities and differences between cultures, in the broadest sense of high culture, popular culture and the customs and practices of everyday life. In this sense it is inherently intercultural" (QAA, 2015, point 2.2).

The responses to the questionnaire confirm that different students have different learning styles. Language tutors also need to acknowledge this and give students the opportunity to enhance their language skills through different means. The translation appeals to those students who like reflecting on the differences between two languages ${ }^{5}$.

Studies on translation as a way of reflecting on morpho-syntactic features (Cook, 2010; George, 1972) demonstrate how this task allows learners to

\footnotetext{
4. See responses to Question 5; https://research-publishing.box.com/s/cihuzkz5v5k71k0511 ghrqj1v8snr76e

5. See responses to Question 5; https://research-publishing.box.com/s/cihuzkz5v5k71k0511ghrqj1v8snr76e
} 
observe not only specific characteristics of the target language, but also observe the correspondence between target language features and their mother tongue equivalents. One student's comment also highlights the importance of using corrections on a written task to improve oral skills. Freed (1995) notes that investment in grammar instruction in the early stages of instruction may result in advances in speaking and listening at the upper intermediate and advanced levels.

Experience suggests that students will only engage with resources if the content is meaningful to them. In this particular context, students can relate the WLW to their existing knowledge of the language. They also understand its usefulness for future progress. This understanding is necessary for the students to respond well to the online resource as well as to independent learning in general.

The students' general feedback on the resource ${ }^{6}$, allowed us to understand how they engaged with it. Their comments show a general concern about the lack of progress in writing skills during the YA and an understanding that regular use of WLW can help to improve the situation.

\subsection{Measurable outcomes}

Although data suggest there has been an improvement in the grades achieved by final-year students in their language exams since the introduction of the WLW, it would be risky to claim that the improvement is directly correlated to the WLW. Too many variables affect students' performances during tests, for example attitude to study and natural predisposition to L2 learning. However, we expect that regular use of the resource will help avoid fossilisation of errors and that this will have a positive impact on the performance in finalyear language exams.

Figure 5 shows students' scores in the grammar exercises, in which $59.4 \%$ of the respondents' scores are in Class I. This is a positive result since most of the

6. See responses to Question 8; https://research-publishing.box.com/s/cihuzkz5v5k71k0511ghrqj 1v8snr76e 
grammar topics in the WLW are very challenging: use of gerund, translation of '-ing forms' in Italian, forms and use of the subjunctive, and the sequence of tenses within 'if clauses'. However, evidence that students can use these forms accurately would be provided only by an in-depth analysis of their language production.

Finally, it would be interesting to evaluate whether the WLW improved language performance in a communicative context. VanPatten's (1996, 2002) investigations show that advanced learners with a wider vocabulary and more control over grammar pay attention to grammatical forms even in a communicative context. A student commented as follows: "the corrections made me rephrase the way in which I said things in daily conversation". This subjective evidence is in line with VanPatten's $(1996,2002)$ studies and is an aspect of the WLW that deserves further investigation.

Figure 5. Grades achieved in grammar exercises

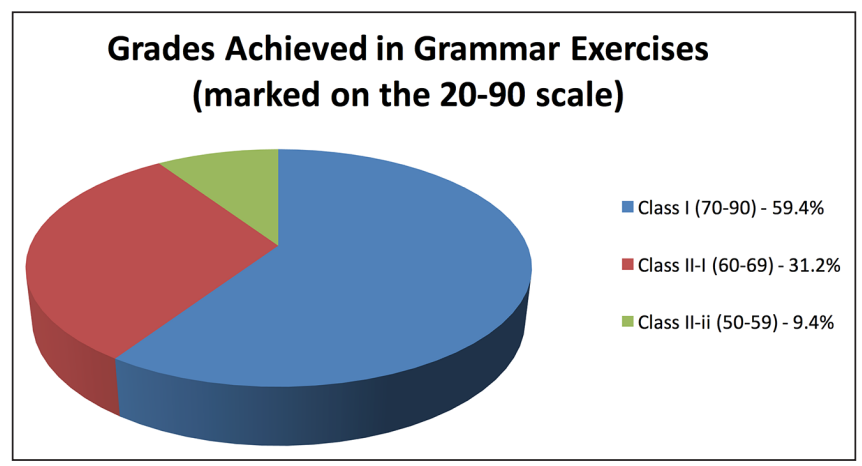

\section{Conclusion}

One of the outcomes at present is student satisfaction, indicated in responses to the questionnaire. In general, most students feel that the materials provided have helped them to reinforce morpho-syntactic structures and increase their ability to learn autonomously. 
The SA experience offers tutors an opportunity to use independent and computerbased learning to create materials aimed at consolidating language competence and facilitating the process of second language acquisition, even at a distance. However, these materials need to be related both to the specific context of students' SA and to the taught programme. In addition, this study has shown that students are more likely to engage with independent and computer-based learning if the connection between independent learning and taught programme is clear to them and if they perceive the learning outcomes as relevant to their needs.

\section{References}

Batstone, R. (2002). Contexts of engagement: a discourse perspective on 'intake' and 'pushed output. System, 30(1), 1-14. https://doi.org/10.1016/S0346-251X(01)00055-0

Collentine, J. (2009). Study abroad research: findings, implications, and future directions. In M. Long \& C. Doughty (Eds), The handbook of language teaching (pp. 218-233). Blackwell Publishing Ltd. https://doi.org/10.1002/9781444315783.ch13

Cook, G. (2010). Translation in language teaching: an argument for reassessment. Oxford University Press.

Freed, B. (Ed.). (1995). Second language acquisition in a study abroad context. John Benjamins. https://doi.org/10.1075/sibil.9

George, H. V. (1972). Common errors in language learning: insights from English. Newbury House.

QAA. (2015). Subject benchmark statement - languages, cultures and societies. http:// www.qaa.ac.uk/en/Publications/Documents/SBS-consultation-Languages-CulturesSocieties-15.pdf

Stern, H. H. (1964). The future of modern languages in the universities. Modern Languages, 45(3), 87-97.

VanPatten, B. (1996). Input processing and grammar instruction. Ablex.

VanPatten, B. (2002). Processing instruction: an update. Language Learning, 52(4), 755-803. https://doi.org/10.1111/1467-9922.00203 


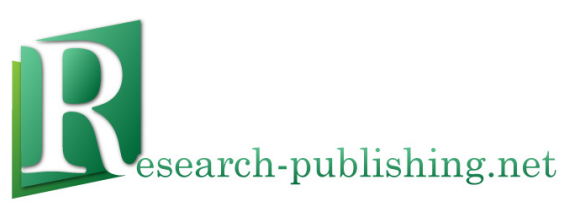

Published by Research-publishing.net, a not-for-profit association

Voillans, France, info@research-publishing.net

(C) 2018 by Editors (collective work)

(C) 2018 by Authors (individual work)

Using digital resources to enhance language learning - case studies in Italian

Edited by Rosalba Biasini and Anna Proudfoot

Rights: The whole volume is published under the Attribution-NonCommercial-NoDerivatives International (CC BY-NC-ND) licence; individual articles may have a different licence. Under the CC BY-NC-ND licence, the volume is freely available online (https://oi.org/10.14705/rpnet.2018.24.9782490057139) for anybody to read, download, copy, and redistribute provided that the author(s), editorial team, and publisher are properly cited. Commercial use and derivative works are, however, not permitted.

Disclaimer: Research-publishing.net does not take any responsibility for the content of the pages written by the authors of this book. The authors have recognised that the work described was not published before, or that it was not under consideration for publication elsewhere. While the information in this book is believed to be true and accurate on the date of its going to press, neither the editorial team nor the publisher can accept any legal responsibility for any errors or omissions. The publisher makes no warranty, expressed or implied, with respect to the material contained herein. While Research-publishing.net is committed to publishing works of integrity, the words are the authors' alone.

Trademark notice: product or corporate names may be trademarks or registered trademarks, and are used only for identification and explanation without intent to infringe.

Copyrighted material: every effort has been made by the editorial team to trace copyright holders and to obtain their permission for the use of copyrighted material in this book. In the event of errors or omissions, please notify the publisher of any corrections that will need to be incorporated in future editions of this book.

Typeset by Research-publishing.net

Cover design by $(\mathrm{C}$ Raphaël Savina (raphael@savina.net)

ISBN13: 978-2-490057-13-9 (Ebook, PDF, colour) ISBN13: 978-2-490057-14-6 (Ebook, EPUB, colour)

ISBN13: 978-2-490057-12-2 (Paperback - Print on demand, black and white)

Print on demand technology is a high-quality, innovative and ecological printing method; with which the book is never 'out of stock' or 'out of print'.

British Library Cataloguing-in-Publication Data.

A cataloguing record for this book is available from the British Library.

Legal deposit, UK: British Library.

Legal deposit, France: Bibliothèque Nationale de France - Dépôt légal: juillet 2018. 